\title{
Effects of Percutaneous Coronary Intervention on Depressive Symptoms in Chronic Stable Angina Patients
}

\author{
Mahn-Won Park ${ }^{1}$ Ji-Hun Kim¹, Sung-Ho Her ${ }^{1}$, Jung-Sun Cho', Min-Seok Choi', \\ Tae-Geun Gweon', II-Nam Ju1, Ju-Yeol Baek', Ki-Bae Seung ${ }^{1}$ and Hyojin Go² \\ ${ }^{1}$ Department of Internal Medicine, College of Medicine, The Catholic University of Korea, Seoul, Republic of Korea \\ 2Department of Psychiatry, College of Medicine, The Catholic University of Korea, Seoul, Republic of Korea
}

Objective Depression is present in 1 of 5 outpatients with coronary artery disease (CAD), and a well-documented risk factor for recurrent cardiac events and mortality. We examined the impact of percutaneous coronary intervention (PCI), on depressive symptoms, in chronic stable angina (CSA) patients.

Methods On prospective and non-randomized trial, consecutive CSA patients $(n=171)$, who had undergone coronary angiography from January 2006 to December 2007, were included. Patients were subdivided into PCI and non-PCI groups, and then completed 21item the Beck Depression Inventory II (BDI-II), at the baseline and pre-discharge, to assess the depressive symptoms.

Results A total of 108 (63\%) patients were assigned to the non-PCI group, and 63 (37\%) patients to the PCI group. Using an independent t-test, we found that patients with PCI were significantly older (non-PCI vs. PCI; $57 \pm 11$ vs. $64 \pm 10$, years, $\mathrm{p}<0.001$ ), had more joint disease ( 12.0 vs. $27.0 \%, \mathrm{p}=0.013$ ), more stroke history ( 5.6 vs. $17.5 \%, \mathrm{p}=0.012$ ) and higher incident of family history of cardiovascular disease ( 28.7 vs. $46.0 \%, \mathrm{p}=0.025)$, but less religion ( 54.6 vs. $36.5, \%, \mathrm{p}=0.002)$ and private health insurance $(43.5$ vs. $20.6, \%, \mathrm{p}=0.002)$. The mean difference of BDI-II score between the baseline and pre-discharge was higher in patients with PCI (OR: 1.266; 95\% CI: 1.146$1.398, \mathrm{p}<0.001)$.

Conclusion In conclusion, PCI contributes independently to higher risk of developing depressive symptoms in CSA patients during hospitalization; Routine assessment and management of PCI related depressive symptoms are justified.

Psychiatry Investig 2012;9:252-256

Key Words Depression, Angioplasty, Coronary artery disease.

\section{INTRODUCTION}

Research over the past decades on the link between depression and coronary artery disease $(\mathrm{CAD})$ has established an epidemiologic association. ${ }^{1}$ Cross-sectional and longitudinal data suggest a bidirectional link between depression and $\mathrm{CAD}^{2}$ Depressive symptoms and depressive disorder are common among myocardial infarction (MI) patients. Approximately $15 \%$ to $20 \%$ of patients, with acute myocardial infarction (AMI), have been identified as experiencing a ma-

Received: August 2, 2011 Revised: April 2, 2012

Accepted: May 3, 2012 Available online: September 6, 2012

$\triangle$ Correspondence: Sung-Ho Her, MD

Department of Internal Medicine, College of Medicine, The Catholic University of Korea, 520-2 Daeheung-dong, Jung-gu, Daejeon 301-723, Republic of Korea

Tel: +82-42-220-9504, Fax: +82-42-226-9686, E-mail: hhhsungho@naver.com

(a) This is an Open Access article distributed under the terms of the Creative Commons Attribution Non-Commercial License (http://creativecommons.org/licenses/by$\mathrm{nc} / 3.0$ ) which permits unrestricted non-commercial use, distribution, and reproduction in any medium, provided the original work is properly cited. jor depressive disorder (MDD).$^{3-5}$ Post-MI depressive symptoms have been shown to be an independent risk factor for mortality. MDD, and even sub-threshold depressive symptoms that do not meet the criteria for a diagnosis of MDD, are risk factors for the development of CAD events in healthy patients, and for recurrent events in patients with established CAD. ${ }^{6}$ Although previous studies have reported depression as a comorbid condition in patients with $\mathrm{CAD}$, there are little reports about the relationship of percutaneous coronary intervention (PCI) and depressive symptoms, among chronic stable angina (CSA) patients. This study is to evaluate whether PCI is associated with the development of depressive symptoms.

\section{METHODS}

\section{Patients and definitions}

This is a prospective study of coronary intervention and 
depressive symptoms in CSA patients, who underwent cardiac catheterizations at Daejeon St. Mary's Hospital, the Catholic University of Korea, from January 2009 to April 2010. Patients were eligible to participate in the study if they had $\geq 50 \%$ stenosis in at least one coronary artery, based on effort angina symptoms consistent with coronary computed tomography, or evidence of exercise induced ischemia by treadmill or cardiac perfusion testing. Patients were excluded if they had one or more of the following characteristics: serum creatinine levels $>2.5 \mathrm{mg} / \mathrm{dL}$; cardiogenic shock; acute MI; MI history; history of PCI; unstable angina; variant angina; history of coronary artery bypass graft surgery; malignancy; autoimmune disease; recent infectious disease; medicated antidepressive and antianxiety drugs; or current and past mood disorders, panic disorder with and without agoraphobia, social phobia, generalized anxiety disorder, and alcohol and substance abuse and dependence. A total of 171 participants were enrolled in the study, and underwent a baseline study examination that included a comprehensive health interview, medical history questionnaire, psychosocial questionnaire, blood samples and echocardiography. The Institutional Review Board approved the protocol, and all participants provided their written informed consent. To assess for the presence of depressive symptoms, within the past month, a trained research assistant administered 21-item the Beck Depression Inventory II (BDIII). ${ }^{7}$ The same set of questionnaires was administered on the day of discharge. Demographic data and medical history were obtained by self-report questionnaire. Age, medical history, family history of cardiovascular disease, religion, private health insurance status, occupation status, smoking, and alcohol use were included in the questionnaire. The parameters were defined of lung disease; chronic obstructive pulmonary disease (COPD), asthma and interstitial lung disease, liver disease; viral hepatitis and liver cirrhosis, gastrointestinal disease; gastritis, peptic ulcer and esophagitis, joint disease; degenerative arthritis and rheumatoid arthritis, regular alcohol use; the frequency of alcohol intake is more than 3 times/ week ${ }^{8}$ and chest pain within 4 weeks; and the existence of effort angina within 4 weeks. We assessed cardiac function, using a resting echocardiogram, for measurement of the left ventricular ejection fraction (Simpson's method). Complete blood count, creatinine, uric acid, fasting glucose, high-density lipoprotein cholesterol, low-density lipoprotein cholesterol, total cholesterol, triglyceride, high sensitivity C-reactive protein, and Hemoglobin A1c were all measured from venous blood samples, after a 12-hour fast.

\section{Statistical analysis}

Patients were grouped, based on the whether the PCI was performed or not, and were compared on clinical and demo- graphic variables. Comparisons of depressive symptoms baseline and pre-discharge were made with the independent t-test in each group. Statistical analyses were performed using the SPSS statistical package, version 18.0 (SPSS Inc., Chicago, IL, USA). Unless otherwise noted, all tests were two-tailed, and a $p$ value of less than 0.05 was considered significant. Potential associations between clinical and biologic parameters were tested by multivariate logistic regression analyses. All data are presented as the means and standard deviations.

\section{RESULTS}

In total, 171 CSA patients were enrolled in the study. Based on angiography, 108 (63\%) cases were assigned to the nonPCI, and 63 (37\%) cases were assigned to the PCI group. Sample population characteristics, with respect to investigated risk variables, are presented in Table 1. Based on independent t-test, patients with PCI were significantly older (non-PCI vs. PCI; $57 \pm 11$ vs. $64 \pm 10$, years, $\mathrm{p}<0.001$ ), had more joint disease (non-PCI vs. PCI; 12.0 vs. $27.0 \%, \mathrm{p}=0.013$ ), higher history of stroke (non-PCI vs. PCI; 5.6 vs. 17.5\%, $\mathrm{p}=0.012$ ) and higher incident of family history of CVD (non-PCI vs. PCI; 28.7 vs. $46.0 \%, \mathrm{p}=0.025$ ). Table 2 includes some selected association factors related to depression, showed less religion (non-PCI vs. PCI; 54.6 vs. $36.5 \%$, $\mathrm{p}=0.002$ ) and less private health insurance (non-PCI vs. PCI; 43.5 vs. $20.6 \%, \mathrm{p}=0.002$ ) in patients with PCI, compared to non-PCI patients. No relevant differences in the baseline laboratory characteristics, except serum uric acid level and left ventricular ejection fraction were significantly different between the two groups (Table 3 ). The baseline BDI-II scores were not statistically different between the two groups (non-PCI vs. PCI; 13.06 vs. $14.44, \mathrm{p}=0.209$ ),

Table 1. Comparison of clinical characteristics between non- $\mathrm{PCl}$ and $\mathrm{PCl}$ groups by independent t-test

\begin{tabular}{lccr}
\hline & $\begin{array}{c}\text { non-PCI } \\
(\mathrm{N}=108)\end{array}$ & $\begin{array}{c}\text { PCI } \\
(\mathrm{N}=63)\end{array}$ & p-value \\
\hline Age (years) & $57 \pm 11$ & $64 \pm 10$ & $<0.001$ \\
Men & $44(40.7)$ & $30(47.6)$ & 0.381 \\
Diabetes mellitus & $21(19.4)$ & $18(28.6)$ & 0.170 \\
Hypertension & $58(53.7)$ & $41(65.1)$ & 0.146 \\
Lung disease & $12(11.1)$ & $7(11.1)$ & 1.000 \\
Gastrointestinal disease & $25(23.1)$ & $17(27)$ & 0.574 \\
Liver disease & $8(7.4)$ & $5(7.9)$ & 0.900 \\
Joint disease & $13(12)$ & $17(27)$ & 0.013 \\
Prior stroke & $6(5.6)$ & $11(17.5)$ & 0.012 \\
Chest pain within 4 weeks & $67(62)$ & $48(76.2)$ & 0.068 \\
Family history of CVD & $31(28.7)$ & $29(46)$ & 0.025 \\
\hline
\end{tabular}

Data are presented as mean \pm SD or number (\%). PCI: percutaneous coronary intervention, CVD: cardiovascular disease 
Table 2. Comparison of association factors and measures of depression between non- $\mathrm{PCl}$ and $\mathrm{PCl}$ groups by independent t-test

\begin{tabular}{lccc}
\hline & $\begin{array}{c}\text { Non-PCI } \\
(\mathrm{N}=108)\end{array}$ & $\begin{array}{c}\text { PCI } \\
(\mathrm{N}=63)\end{array}$ & p-value \\
\hline Having religion & $59(54.6)$ & $19(36.5)$ & 0.002 \\
Employed & $35(32.4)$ & $13(30.2)$ & 0.098 \\
Private health insurance & $47(43.5)$ & $13(20.6)$ & 0.002 \\
Current smoking & $26(24.1)$ & $18(28.6)$ & 0.516 \\
Regular alcohol use & $36(33.3)$ & $24(38.1)$ & 0.529 \\
BDI-II score (baseline) & $13.06 \pm 6.64$ & $14.44 \pm 7.45$ & 0.209 \\
BDI-II score & $11.80 \pm 6.97$ & $18.49 \pm 8.14$ & $<0.001$ \\
(pre-discharge) & & & \\
\hline
\end{tabular}

Data are presented as mean \pm SD or number (\%). PCI: percutaneous coronary intervention, BDI-II: Beck Depression Inventory II

Table 3. Comparison of laboratory findings and left ventricular ejection fraction between non- $\mathrm{PCl}$ and $\mathrm{PCl}$ groups by independent t-test

\begin{tabular}{lccc}
\hline & $\begin{array}{c}\text { Non-PCI } \\
(\mathrm{N}=108)\end{array}$ & $\begin{array}{c}\text { PCI } \\
(\mathrm{N}=63)\end{array}$ & p-value \\
\hline Hemoglobin $(\mathrm{g} / \mathrm{dL})$ & $13.5 \pm 1.6$ & $13.2 \pm 1.5$ & 0.170 \\
Platelet count $\left(\times 10^{9} / \mathrm{L}\right)$ & $23.0 \pm 6.5$ & $23.6 \pm 7.2$ & 0.550 \\
Creatinine phosphokinase & $100.5 \pm 71.2$ & $93.6 \pm 87.0$ & 0.583 \\
$\quad$ IU/L) & & & \\
Creatinine (mg/dL) & $0.78 \pm 0.36$ & $0.82 \pm 0.27$ & 0.548 \\
Uric acid (mg/dL) & $4.56 \pm 1.58$ & $5.11 \pm 1.88$ & 0.046 \\
Total cholesterol (mg/dL) & $181.2 \pm 36.5$ & $184.7 \pm 54.1$ & 0.612 \\
HDL cholesterol (mg/dL) & $47.2 \pm 12.5$ & $43.6 \pm 13.3$ & 0.076 \\
LDL cholesterol (mg/dL) & $119.3 \pm 46.2$ & $116.4 \pm 34.9$ & 0.673 \\
Triglyceride (mg/dL) & $161.8 \pm 92.0$ & $223.5 \pm 284.2$ & 0.102 \\
hsCRP (mg/dL) & $0.47 \pm 1.86$ & $0.44 \pm 1.14$ & 0.927 \\
Hemoglobin A1c (\%) & $6.69 \pm 1.29$ & $7.16 \pm 1.33$ & 0.193 \\
Left ventricular ejection & $67.2 \pm 6.6$ & $65.6 \pm 8.7$ & 0.183 \\
fraction $(\%)$ & & & \\
\hline
\end{tabular}

Data are presented as mean \pm SD. PCI: percutaneous coronary intervention, hsCRP: high sensitivity C-reactive protein, HDL-C: high density lipoprotein cholesterol, LDL-C: low density lipoprotein cholesterol

but there was a statistically significant increment of the BDIII scores in the PCI group (non-PCI vs. PCI; 11.80 vs. 18.49, $\mathrm{p}<0.001$ ), while no significant changes were found in the nonPCI group (Table 2, Figure 1). By a multivariate logistic regression analysis, PCI was associated with a $26.3 \%$ (OR: 1.263; 95\% CI: 1.146-1.398, $\mathrm{p}<0.001)$ increased risk of depressive symptoms during hospitalization (Table 4).

\section{DISCUSSION}

In the Heart and Soul study of 1,017 patients with stable $\mathrm{CAD}$, the baseline depressive symptoms assessed using the

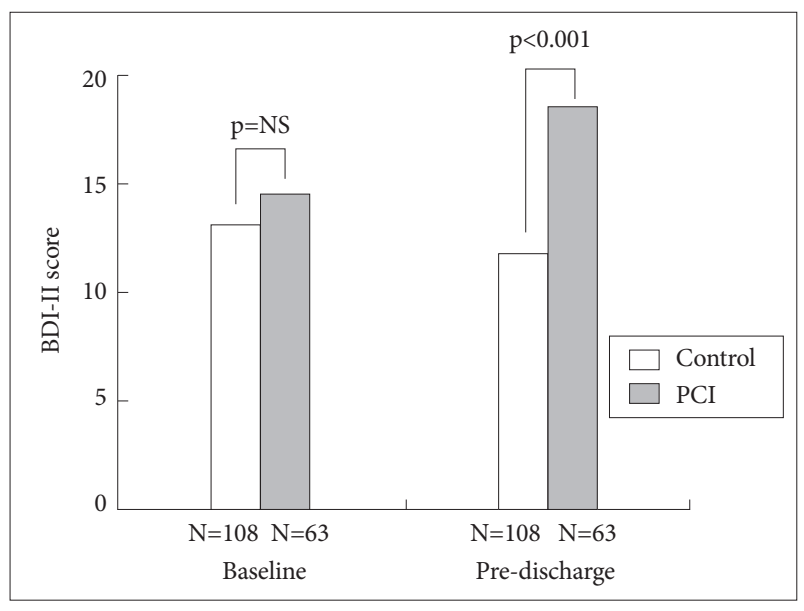

Figure 1. Comparison of measures of depression between non$\mathrm{PCl}$ and $\mathrm{PCl}$ groups during hospitalization. $\mathrm{PCl}$ : percutaneous coronary intervention, BDI-II: Beck Depression Inventory II.

Patient Health Questionnaire (PHQ), 19.6\% had depressive symptoms ( $\mathrm{PHQ} \geq 10$ ), and they had $10 \%$ of the age-adjusted annual rate of cardiovascular events, compared to $6.7 \%$, among the participants without depressive symptoms (hazard ratio, $1.50 ; 95 \%$ confidence interval, $1.16-1.95 ; \mathrm{p}=0.002)$. In this sample, the association between depressive symptoms and adverse cardiovascular events was largely explained by behavioral factors, particularly physical inactivity. ${ }^{9}$ Also the experience of CAG and/or PCI is a significant event to stable $\mathrm{CAD}$ patients. Uncertainty related to diagnosis and outcome is reported to be patients' major concern pre-procedure. Patients may also experience anxiety, due to the circumstances preceding the angiography and/or PCI. ${ }^{10}$ During CAG and/or $\mathrm{PCI}$, patients experience puncture pain and discomfort of lying still, sound environment, and supine position for prolonged periods, after manual sheath removal. Typically after PCI, patients are transferred to an intensive care unit (ICU), required complete bed rest with the affected leg restrained to prevent mobility and exposed to the special environment related to ICU. Ninety-one percent of the hospitals reported continuing to treat the patient with bed rest for an additional 6 hours, after the sheath is removed. ${ }^{11}$ Patients excluded from the same-day discharge after PCI for safety concerns were reported to have worse early and late outcomes. ${ }^{12}$

Several studies have now reported that patients who experience angina are more aware of physical symptoms, in general, than are those with silent ischemia. ${ }^{13}$ Our results raise the question of whether somatic hypersensitivity, a well-known and common manifestation of depression and anxiety, ${ }^{14} \mathrm{mi}-$ ght not determine whether the patient with coronary artery disease experience or report angina. A number of chronic pain conditions are known to lower pain thresholds. ${ }^{15,16}$

Scores of 14 or greater, on the BDI-II, were considered indicative of at least mild to moderate symptoms of depression 
Table 4. By multivariate logistic regression analysis, relationships between $\mathrm{PCl}$ and measures of depression

\begin{tabular}{|c|c|c|c|c|}
\hline & Non-PCI (N=108) & PCI $(\mathrm{N}=63)$ & OR (95\% CI) & $\mathrm{p}$-value \\
\hline $\begin{array}{l}\text { Mean difference between discharge and } \\
\text { baseline in BDI-II score }\end{array}$ & $-1.26 \pm 4.23$ & $4.05 \pm 4.57$ & $1.266(1.146-1.398)$ & $<0.001$ \\
\hline Uric acid & $4.56 \pm 1.58$ & $5.11 \pm 1.88$ & $1.242(0.941-1.638)$ & 0.126 \\
\hline Having religion & $59(54.6)$ & $19(36.5)$ & $0.650(0.273-1.546)$ & 0.330 \\
\hline Private health insurance & $47(43.5)$ & $13(20.6)$ & $0.646(0.219-1.908)$ & 0.429 \\
\hline Family history of CVD & $31(28.7)$ & $29(46)$ & $1.945(0.768-4.922)$ & 0.160 \\
\hline Prior stroke & $6(5.6)$ & $11(17.5)$ & $1.415(0.325-6.157)$ & 0.644 \\
\hline Age (years) & $57 \pm 11$ & $64 \pm 10$ & $1.044(0.992-1.099)$ & 0.096 \\
\hline Joint disease & $13(12)$ & $17(27)$ & $1.814(0.585-5.623)$ & 0.302 \\
\hline Men & $44(40.7)$ & $30(47.6)$ & $0.629(0.228-1.735)$ & 0.371 \\
\hline
\end{tabular}

PCI: percutaneous coronary intervention, BDI-II: Beck Depression Inventory II, CVD: cardiovascular disease

(elevated depression symptoms). ${ }^{7}$ In this study of 171 in-hospital patients with CSA, we found relatively borderline depression level of basal BDI-II in both groups, without significant difference, between the two groups (non-PCI vs. PCI; 13.06 vs. $14.44, \mathrm{p}=0.209$ ). However, patients who underwent PCI had a $26.3 \%$ greater rate of subsequent depressive symptoms than patients of CAG, only. Our results suggest that PCI and peri-procedural managements are an important risk factor in the subsequent depressive mood status of patient with stable CAD, during hospitalization.

As previous studies have demonstrated, an association between depressive symptoms and health status outcomes in patients with coronary disease, ${ }^{17-19}$ we should include assessment and treatment of depressive symptoms for better health outcomes. ${ }^{20}$ In one study, reducing the emotional distress may improve long-term mortality in CAD patients. ${ }^{21}$ As treatment of depression is complex, and antidepressant may have potential for cardiotoxicity, many cardiovascular physicians are either uncomfortable treating depression and/or using antidepressant medications in their patients with CAD. ${ }^{22}$ But recent large studies showed that SSRIs can generally be used with reasonable safety and efficacy in cardiac patients, as a first line mediation. ${ }^{23,24}$ In addition, cognitive-behavioral treatment (CBT), a specific form of psychotherapy found to be highly efficacious in the treatment of depression. ${ }^{25}$

We are aware of several limitations of our study. It was conducted at a single center, enrolled small number of patients, and of CSA angina patients only. Also, other parameters of mood (ex. Anxiety) were not researched. Long-term followup of major cardiovascular events, associated with depressive symptoms, was needed, too.

In conclusion, this study identified that a significant proportion of CSA patients had borderline depressive symptoms, and PCI can independently cause depressive symptom, during hospitalization. Once patients are identified as depressive, appropriate interventions are required that might effectively manage depressive symptoms. In addition, more careful periprocedural managements, including ICU care, may be effective to prevent the development of post-PCI depression for each patient. Further research is warranted to identify the mechanisms of PCI and depression, as well as to examine the proper interventions for depressive CSA patients.

\section{REFERENCES}

1. Frasure-Smith N, Lesperance F. Recent evidence linking coronary heart disease and depression. Can J Psychiatry 2006;51:730-737.

2. Khawaja IS, Westermeyer JJ, Gajwani P, Feinstein RE. Depression and coronary artery disease: the association, mechanisms, and therapeutic implications. Psychiatry (Edgmont) 2009;6:38-51.

3. Schleifer SJ, Macari-Hinson MM, Coyle DA, Slater WR, Kahn M, Gorlin R, et al. The nature and course of depression following myocardial infarction. Arch Intern Med 1989;149:1785-1789.

4. Hance M, Carney RM, Freedland KE, Skala J. Depression in patients with coronary heart disease. A 12-month follow-up. Gen Hosp Psychiatry 1996;18:61-65.

5. Bush DE, Ziegelstein RC, Tayback M, Richter D, Stevens S, Zahalsky H, et al. Even minimal symptoms of depression increase mortality risk after acute myocardial infarction. Am J Cardiol 2001;88:337-341.

6. Whooley MA. Depression and cardiovascular disease: healing the broken-hearted. JAMA 2006;295:2874-2881.

7. Beck AT, Steer RA, Brown GK. Beck Depression Inventory, 2nd Edition. San Antonio: Psychological Corp; 1996.

8. Chan AM, von Muhlen D, Kritz-Silverstein D, Barrett-Connor E. Regular alcohol consumption is associated with increasing quality of life and mood in older men and women: the Rancho Bernardo Study. Maturitas 2009;62:294-300.

9. Whooley MA, de Jonge P, Vittinghoff E, Otte C, Moos R, Carney RM, et al. Depressive symptoms, health behaviors, and risk of cardiovascular events in patients with coronary heart disease. JAMA 2008;300:23792388.

10. Gallagher R, Trotter R, Donoghue J. Preprocedural concerns and anxiety assessment in patients undergoing coronary angiography and percutaneous coronary interventions. Eur J Cardiovasc Nurs 2010;9:38-44.

11. Juran NB, Smith DD, Rouse CL, DeLuca SA, Rund M. Survey of current practice patterns for percutaneous transluminal coronary angioplasty. SANDBAG Nursing Coordinators. Am J Crit Care 1996;5:442448.

12. Bertrand OF, Rodes-Cabau J, Larose E, Proulx G, Gleeton O, Nguyen 
$\mathrm{CM}$, et al. Early and late outcomes in patients excluded from same-day home discharge after transradial stenting and maximal antiplatelet therapy. Catheter Cardiovasc Interv 2008;72:619-625.

13. Barsky AJ, Hochstrasser B, Coles NA, Zisfein J, O’Donnell C, Eagle KA. Silent myocardial ischemia. Is the person or the event silent? JAMA 1990;264:1132-1135.

14. Swartz M, Landerman R, George LK, Blazer DG, Escobar J. Somatization Disorder. In: Robins LN, Regier DA, Editors. Psychiatric Disorders in America: The Epidemiological Catchment Area Study. New York, NY: The Free Press, 1991, p.220-257.

15. Bouckoms AJ, Hackett TP. Pain Patients. In: Cassem NH, Stern TA, Rosenbaum JF, Jellinek MS, Editors. Massachusetts General Hospital Handbook of General Hospital Psychiatry. St. Louis, Mo: Mosby, 1997, p.367-414.

16. Pilowsky I. Affective disorders and pain. In: Dubner R, Gebhart GF and Bond MR, Editors., Proceedings of the 5th World Congress on Pain. Amsterdam, The Netherland: Elsevier; 1988.

17. Ruo B, Rumsfeld JS, Hlatky MA, Liu H, Browner WS, Whooley MA. Depressive symptoms and health-related quality of life: the heart and soul study. JAMA 2003;290:215-221.

18. Sullivan MD, LaCroix AZ, Spertus JA, Hecht J. Five-year prospective study of the effects of anxiety and depression in patients with coronary artery disease. Am J Cardiol 2000;86:1135-1138.
19. Spertus JA, McDonell M, Woodman CL, Fihn SD. Association between depression and worse disease-specific functional status in outpatients with coronary artery disease. Am Heart J 2000;140:105-110.

20. Spertus JA, Jones P, McDonell M, Fan V, Fihn SD. Health status predicts long-term outcome in outpatients with coronary disease. Circulation 2002;106:43-49.

21. Denollet J, Brutsaert DL. Reducing emotional distress improves prognosis in coronary heart disease: 9-year mortality in a clinical trial of rehabilitation. Circulation 2001;104:2018-2023.

22. Feinstein RE, Blumenfield M, Orlowski B, Frishman WH, Ovanessian S. A national survey of cardiovascular physicians' beliefs and clinical care practices when diagnosing and treating depression in patients with cardiovascular disease. Cardiol Rev 2006;14:164-169.

23. Glassman AH, O'Connor CM, Califf RM, Swedberg K, Schwartz P, Bigger JT Jr, et al. Sertraline treatment of major depression in patients with acute MI or unstable angina. JAMA 2002;288:701-709.

24. Nickels MW, Privitera MR, Coletta M, Sullivan P. Treating depression: psychiatric consultation in cardiology. Cardiol J 2009;16:279-293.

25. Berkman LF, Blumenthal J, Burg M, Carney RM, Catellier D, Cowan MJ, et al. Effects of treating depression and low perceived social support on clinical events after myocardial infarction: the Enhancing Recovery in Coronary Heart Disease Patients (ENRICHD) Randomized Trial. JAMA 2003;289:3106-3116. 